\title{
Abdominal Obesity and High-sensitivity C-reactive Protein Level among Malay Obese Adults in Kuantan, Malaysia
}

Siti Zuhaidah Shahadan ${ }^{\text {a }}$ (M.Sc.), Azlina Daud ${ }^{\mathrm{a}}$ (Ph.D), Muhammad Lokman Md. Isa ${ }^{\mathrm{b}}$ (Ph.D), Ali Aminuddin Mohd Rasani ${ }^{\mathrm{a}}$ (M.Sc), Muhammad Ibrahim ${ }^{c}$ (Ph.D), Samsul Deraman ${ }^{\mathrm{d}}$ (M.Sc., F.Med)

${ }^{a}$ Department of Medical Surgical Nursing, Kulliyyah of Nursing, IIUM, Kuantan.

${ }^{\mathrm{b}}$ Department of Basic Medical Sciences for Nursing, Kulliyyah of Nursing, IIUM, Kuantan.

${ }^{c}$ Department of Nutrition, Kulliyyah of Allied Health Sciences, IIUM, Kuantan.

${ }^{\mathrm{d}}$ Department of Family Medicine, Kulliyyah of Medicine, IIUM, Kuantan.

\section{ABSTRACT}

Introduction: Abdominal obesity and inflammation are two independent risk factors for cardiovascular disease. However, the inter-relationship between these two factors among Malay population is fragmented. The purpose of this study is to determine the association between waist circumference as a measure of abdominal obesity and high-sensitivity $\mathrm{C}$-reactive protein as an indicator of inflammation status among Malay obese adults in Kuantan, Pahang. Materials and Methods: Ninety-three apparently healthy obese adults (BMI between 27.5 and $39.9 \mathrm{~kg} / \mathrm{m}^{2}$ ) aged between 20 to 62 years old were recruited in this study $(68 \%$ men and $32 \%$ women). Circumference tape was used to measure the waist circumference and fasting venous blood was obtained to determine the high-sensitivity C-reactive protein level. Results: On average, the waist circumference of obese men and women was $103 \mathrm{~cm}(S D=8.7)$ and $94 \mathrm{~cm}(S D=7.0)$, respectively. The median (IQR) of the hs-CRP level of the study participant was $3.80 \mathrm{mg} / \mathrm{L}(1.5,10.1)$. The Kendall's Tau correlation reveals that there is a significant positive linear correlation between waist circumference and hs -CRP level in obese men $(r(30)=0.355, p=0.006)$ and women $(r(63)=0.177, p=0.043)$. Conclusion: There is a significant inter-relationship between waist circumference and hs-CRP level among apparently healthy obese adults in Kuantan, Pahang. This study suggests that assessment of hs-CRP level is beneficial to predict the risk for future cardiovascular disease event and facilitate the management of obesity in this population. A prospective clinical study is recommended to confirm the findings.

KEYWORDS: obesity, inflammation, adults

\section{INTRODUCTION}

The Malaysian Health Facts in 2016 stated that cardiovascular disease (CVD) remained the highest cause of mortality in the Malaysian adults population. ${ }^{1}$ Two of the most important risk factors for CVD are abdominal obesity (AO) and inflammation (elevated C-reactive protein (CRP) or other inflammatory markers). ${ }^{2} \mathrm{AO}$ can be defined as the distribution of adipose tissue around and in the abdomen. ${ }^{3}$ In detail, abdominal adiposity also known as visceral or central obesity refers to the distribution of fat located around the viscera and within the peritoneum, the dorsal border of the intestines and the ventral surface of the kidney. ${ }^{4}$ The distinctive characteristics of adipose tissue that accumulates at the intra-abdominal area is that it releases free fatty acids (FFAs) that enter the bloodstream towards the liver which stimulates

Corresponding author:

Azlina Daud

Kulliyyah of Nursing

International Islamic University Malaysia (IIUM)

Kuantan, Pahang

Tel: +60193241022 ,

Email:damia@iium.edu.my the hepatic glucose production. ${ }^{5}$ The process then disturbs the insulin signaling pathway thus promoting insulin resistance $(\mathbb{I R})^{6}$, which is defined as a clinical state in which a normal or elevated insulin level inhibits the stimulation of several metabolic pathways that are actively involved in the pathogenesis of cardiovascular diseases. ${ }^{2}$

In addition to $\mathrm{AO}$, inflammation also involves in the pathogenesis of atherosclerosis and CVD. ${ }^{7}$ Originally, inflammation is a protective mechanism of the body that involves an ordered sequence of events to protect the tissue in response to injury or destruction of tissue by destroying or diluting both the injurious agent and the injured tissue. ${ }^{8}$ However, in the event of persistent low-grade inflammation, the elevated level of proinflammatory cytokines stimulates the production of C-reactive protein (CRP), which leads to the atherothrombosis formation that consequently increases the cardiovascular risk of an individual. ${ }^{7} \mathrm{C}$ reactive protein (CRP) is a pentameric protein, which originates in the liver and is secreted into the bloodstream. The measurement of CRP in the blood provides a reliable marker of chronic inflammation caused by infectious and other inflammatory agents. ${ }^{9}$ CRP was first discovered in 1930, but the association between CRP and CVD was only reported 
after 60 years. ${ }^{10}$ With the current technology, the available high-sensitivity C-reactive protein (hs-CRP) assay allows the detection of even mild elevation of CRP within the normal range $(<3 \mathrm{mg} / \mathrm{L}){ }^{11}$ The hsCRP level could predict the risk of future CVD events that adds prognostic information to lipid screening, to metabolic syndrome, and to the Framingham Risk Score. ${ }^{12}$ According to a systematic review by Choi, Joseph, \& Pilote, the authors found that in general, obesity in North American, European and Asian adult was associated with elevated levels of CRP and the association was stronger in women compared from men. ${ }^{13}$

Nevertheless, there was also evidence that shows elevated hs-CRP was more predictive of cardiovascular mortality in the non-obese compared from the obese adults with stable coronary heart disease. ${ }^{14}$ Therefore, it is uncertain whether hs-CRP is a robust biomarker of cardiovascular disease (CVD) in obesity population. Furthermore, there is still a lack of data on the hs-CRP level, thus limited evidence to support the importance of conducting hs-CRP testing in healthy obese adults in Malaysia. According to Ridker, inflammation plays a major role in the pathogenesis of cardiovascular disease, including the early development of atherosclerosis. ${ }^{15}$ Although the relationship between obesity, inflammation and cardiovascular disease is well-established $^{8,16,17}$, the role of hs-CRP level in abdominal obesity is less clear. ${ }^{14,18}$ Therefore, this study aims to describe the waist circumference as a measure of abdominal obesity and inflammation status based on the hs-CRP level among Malay obese adults in Kuantan, Pahang.

Pahang is the largest state in Peninsular Malaysia and situated in the eastern coastal region. There are eleven districts in Pahang and Kuantan holds the largest population (approximately 1.6 million).$^{19}$ The prevalence of $\mathrm{AO}$ in Pahang was $48.8 \%$, which are higher than the average Malaysian adult population $(48.6 \%)$. By ethnicity, the prevalence of $A O$ was greater in Indian adult population $(66.2 \%)$ as compared to Malay $(50.7 \%){ }^{20}$ However, as the largest population in Pahang is Malay (approximately 1.2 million, $75 \%$ of total Pahang population) ${ }^{19}$, this study focuses on Malay adults with the understanding that the findings may contribute to a significant impact on the management of obesity towards the largest population of Pahang state. This study also aims to determine the relationship between waist circumference and hs-CRP serum level. In Malaysia, routine assessment of hs-CRP level among apparently healthy obese adults is not required. Thus, presenting the association between waist circumferences as a measure of $\mathrm{AO}$ and hs-CRP level may provide an insight to the health practitioner on the potential usage of the hs-CRP as a biomarker of obesity in obese adults' population in Malaysia.

\section{MATERIALS AND METHOD} Study design
This is a cross-sectional study design that uses convenience sampling method. The participants were recruited from health screening activities and via social media postings. The inclusion criteria of the participants includes obese class I and II as defined by the body mass index (BMI) [obese class I (BMI=27.5-34.9), obese class II (BMl $\left.=35-39.9 \mathrm{~kg} / \mathrm{m}^{2}\right]$ , aged between 19 to 65 years old, living in Kuantan and volunteered with a written informed consent. All participants who are pregnant, breastfeeding, self-reported to have been diagnosed with any chronic diseases are excluded from the study. The sample size was calculated based on the prevalence of obese class I and II adults reported in the National Health Morbidity and Mortality Survey 2014 (NHMS 2014). Using the online Epi Info sample size calculator, a total of 123 participants is needed to represent $80 \%$ of the total distribution of obese class I and II adults in Pahang with 10\% of dropout rate. The data collection was conducted in IIUM Primary Care Clinic, Kuantan.

\section{Outcomes measurements}

There are two outcome measurements assessed in this study. Firstly, the waist circumference (WC) is measured using a non-elastic circumference measuring tape (SECA 203). The participants were reminded to wear light weighted clothing during the data collection day. One researcher was assigned to measure the WC for all participants to reduce the intra-observer bias. The WC measuring process involves the researcher to stand with 25 to $30 \mathrm{~cm}$ feet apart from the participant and the circumference tape is placed on the midway between the inferior margin of the last rib and the crest of the ilium. Additionally, the researcher ensures that the circumference tape was snugly fit but not compressing the soft tissue. Then, the WC level measurement was recorded to the nearest of $0.1 \mathrm{~cm}$. The cut-off points to define elevated waist circumference level, or abdominal obesity (AO) were more than $90 \mathrm{~cm}$ for men and more than $80 \mathrm{~cm}$ for women. ${ }^{3}$

Secondly, the hs-CRP was measured after an overnight fasting. A $5 \mathrm{ml}$ of venous blood was drawn from the antecubital fossa of the participant and filled a plain tube. Within 2 hours after the blood taking procedure, the blood sample was sent to the laboratory. The hs-CRP was analysed using the immunoturbidity method. Before analysing, the blood samples were centrifuged at 1100-2000g for a minimum of 10 minutes. After both measurements had been obtained, a light breakfast and an honorarium were given to the participant. The cutoff points to define elevated hs-CRP level were more than $3 \mathrm{mg} / \mathrm{L}$, as recommended by Nagasawa, which indicates a low-grade inflammation. ${ }^{21}$ Also, based on the analysis of the hs-CRP level of more than 5000 healthy American men and women, a risk estimates to represent individuals with low, mild, moderate, high, and the highest relative risks of future cardiovascular disease were established. ${ }^{22}$ 
The hs-CRP level of the participant was categorized to present the relative risk of future CVD event based on the classification.

\section{Statistical analysis}

Statistical analysis was done using SPSS Version 21. The demographic and anthropometric characteristics were described using either frequency and percentage or mean $(M)$ and standard deviation (SD). The relationship between waist circumference and the hs-CRP level was analysed using Kendall's Tau correlation test because of the non-normally distribution of the data. A p-value of less than 0.05 was considered as significant.

\section{RESULTS}

\section{Demographic characteristics}

The total number of participants recruited in this study was 93 apparently healthy obese adults from Kuantan, Pahang, Malaysia. The mean age of the participant was 33.6 years old $(S D=9.62)$ and ranged from 20 to 62 years old. The majority of the participants was women (68\%), married (59\%), and employed (58\%). More than half of the participants were having a monthly income of less than RM1,500 (51\%) and non-smoker (see Table I).

Table I: Distribution of the study participants by demographic characteristics and anthropometric measurements ( $\mathrm{n}=93$ )

\begin{tabular}{|c|c|c|c|}
\hline Characteristics & Frequency $(n)$ & Percentage (\%) & Mean \\
\hline \multicolumn{4}{|l|}{ Gender } \\
\hline Men & 30 & 32 & \\
\hline Women & 63 & 68 & \\
\hline Age (years) & & & $33.6(9.62)$ \\
\hline \multicolumn{4}{|l|}{ Age group } \\
\hline 20-29 years & 39 & 42 & \\
\hline 30-39 years & 31 & 33 & \\
\hline 40-49 years & 14 & 15 & \\
\hline $50-59$ years & 8 & 9 & \\
\hline$>60$ years & 1 & 1 & \\
\hline \multicolumn{4}{|l|}{ Marital status } \\
\hline $\begin{array}{l}\text { Single } \\
\text { Married }\end{array}$ & $\begin{array}{l}34 \\
55\end{array}$ & $\begin{array}{l}37 \\
59\end{array}$ & \\
\hline Divorced/widowed & 4 & 4 & \\
\hline \multicolumn{4}{|l|}{ Employment status } \\
\hline Student & 25 & 27 & \\
\hline Employed & 54 & 58 & \\
\hline Unemployed & 2 & 2 & \\
\hline Homemaker & 12 & 13 & \\
\hline \multicolumn{4}{|l|}{ Educational background } \\
\hline Certificates & 3 & 3.2 & \\
\hline Sijil Pelajaran Malaysia & 20 & 21.5 & \\
\hline Matriculation & 16 & 17.2 & \\
\hline Diploma & 12 & 12.9 & \\
\hline Degree & 31 & 33.3 & \\
\hline Master & 9 & 9.7 & \\
\hline Doctor of philosophy & 2 & 2.2 & \\
\hline \multicolumn{4}{|l|}{ Income status } \\
\hline$<\mathrm{RM} 1,500$ & 48 & 51 & \\
\hline $\mathrm{RM} 1,501-\mathrm{RM} 3,000$ & 22 & 24 & \\
\hline $\mathrm{RM} 3,001-\mathrm{RM} 4,500$ & 11 & 12 & \\
\hline $\mathrm{RM} 4,501-\mathrm{RM} 6,000$ & 8 & 9 & \\
\hline$>\mathrm{RM} 6,001$ & 4 & 4 & \\
\hline \multicolumn{4}{|l|}{ Smoking status } \\
\hline Current smoker & 5 & 5 & \\
\hline Former smoker & 7 & 8 & \\
\hline Never smoking & 81 & 87 & \\
\hline \multicolumn{4}{|c|}{ Anthropometric measurements } \\
\hline Height $(\mathrm{cm})$ & & & $159.22(8.54)$ \\
\hline Weight (kg) & & & $80.27(12.81)$ \\
\hline Body mass index $\left(\mathrm{kg} / \mathrm{m}^{2}\right)$ & & & $31.54(3.26)$ \\
\hline
\end{tabular}




\section{Anthropometry analysis}

Table I presents the anthropometric measurements and Table II shows the prevalence of obesity classes. As can be seen in Table I, the mean height and weight of the participant were $159.22 \mathrm{~cm}$ (SD = $8.54)$ and $80.27 \mathrm{~kg}(S D=12.81)$, respectively. In Table II, the distribution of the participants based on the international and Asian BMI classification was presented. The international BMI classification was based on the World Health Organization (WHO) guideline. ${ }^{23}$ On the other hand, the Asian BMI classification was based on the Clinical Practice Guideline (CPG) for the Management of Obesity. ${ }^{3}$ The findings as stated in Table II shows that majority of the participants were classified as preobese $(43 \%)$ based on the international BMI cut-off points and as obesity class I $(81.7 \%)$ based on the Asian BMI cut-off points. Using the international BMI cut-off points, the prevalence of pre-obese and obesity class I was higher in men $(46.7 \%$ and $40 \%$, respectively), but the prevalence of obesity class I was higher in women $(20.6 \%)$ as compared to men (13.3\%). Similarly, according to the Asian cut-off points of BMI, the prevalence of obesity class I was higher in men $(87 \%)$ while obesity class II was greater among women (21\%).

Relationship between waist circumference and high-sensitivity C-reactive protein level

Table III describes the distribution of waist circumference and hs-CRP level among obese adults in Kuantan, Pahang. The distribution of waist circumference in a sample of 30 obese men was non -normally distributed, with skewness of 1.13 (Standard error $(S E)=0.427$ ) and kurtosis of 0.53 (SE $=0.833)$. A $50 \%$ of the obese men had waist circumference measurements at $100.8 \mathrm{~cm}$ or less. Typically the waist circumference measurements of obese men were between $95 \mathrm{~cm}$ to $107.5 \mathrm{~cm}$. Two obese men had exceptionally high waist circumference measurements of $123.5 \mathrm{~cm}$ and 124 $\mathrm{cm}$. On the other hand, the distribution of waist circumference in a sample of 63 obese women was approximately symmetric, and the average waist circumference measurement was $94.2 \mathrm{~cm}$ (SD = 7.03). It is $95 \%$ confident that the mean waist circumference measurements of obese women in this study are between $94.2 \mathrm{~cm}$ and $95.9 \mathrm{~cm}$. A Mann -Whitney test indicated that the distribution of waist circumference measurement was statistically significantly higher among men than women $(U=$ 411.5, $p<0.001)$.

For the hs-CRP, the distribution for both obese men and women was non-normally distributed. The skewness and kurtosis in the sample of obese men were $1.80(S E=0.43)$ and $3.74(S E=0.83)$, respectively. For women, the skewness and kurtosis of the sample distribution were $1.06(S E=0.30)$ and $0.43(S E=0.60)$, respectively. The median hs-CRP level of obese men $(n=30)$ was $2.55 \mathrm{mg} / \mathrm{L}$, and on average, the hs-CRP level falls within the range between 1.0 and $6.1 \mathrm{mg} / \mathrm{L}$. On the other hand, half of the obese women $(n=63)$ has an hs-CRP level at $5.80 \mathrm{mg} / \mathrm{L}$ or less. The middle $50 \%$ of hs-CRP level among women was between 2.1 and $11.5 \mathrm{mg} / \mathrm{L}$. A Mann-Whitney test indicated that the distribution of hs-CRP level was statistically significantly higher among women than men $(U=601, p=0.005)$.

The non-parametric Kendall's Tau correlation test has been carried out to find out the association between waist circumference and hs-CRP level among obese men and women in this study. The findings indicate that there was a weak strength, positive linear relationship between waist circumference and hs-CRP level in obese men and Kendall's Tau correlation shows that the relationship was significant, $r(30)=0.355, p=0.006$. Similarly, the findings show that there was also a significant positive linear relationship between waist circumference and hs-CRP level in obese women ( $r$ $(63)=0.177, p=0.043)$. However, the strength of the correlation was very weak.

Table II. Distribution of study participants by obesity classification according to international and Asian cut-off points $(n=93)$

\begin{tabular}{|c|c|c|c|c|}
\hline \multirow{2}{*}{ BMI $\left(\mathrm{kg} / \mathrm{m}^{2}\right)$} & \multirow{2}{*}{ BMI categories } & \multicolumn{3}{|c|}{ International classification* } \\
\hline & & Men & Women & Total \\
\hline $25.0-29.9$ & Pre-obese & $14(46.7)$ & $26(41.3)$ & $40(43)$ \\
\hline $30.0-34.9$ & Obese I & $12(40.0)$ & $24(38.1)$ & $36(38.7)$ \\
\hline $35.0-39.9$ & Obese II & $4(13.3)$ & $13(20.6)$ & $17(18.3)$ \\
\hline \multirow{2}{*}{ BMI $\left(\mathrm{kg} / \mathrm{m}^{2}\right)$} & \multirow{2}{*}{ BMI categories } & \multicolumn{3}{|c|}{ Asian classification** } \\
\hline & & Men & Women & Total \\
\hline $27.5-34.9$ & Obese I & $26(87)$ & $50(79)$ & $76(81.7)$ \\
\hline $35-39.9$ & Obese II & $4(13)$ & $13(21)$ & $17(18.3)$ \\
\hline
\end{tabular}

Note:

All data presented in frequency (percentage)

*International cut-off points are based on the World Health Organization (WHO) guideline ${ }^{23}$

${ }^{* *}$ Asian cut-off points are based on the Clinical Practice Guideline for the Management of Obesity ${ }^{3}$ 
Also, this study presents the prevalence of abdominal obesity based on the Asian cut-off points of waist circumference ${ }^{3}$ and elevated hs-CRP based on the cut-off points recommended by Nagasawa (2009) (see Table IV). This study found that the prevalence of abdominal obesity among obese adults is $100 \%$ for men and $98.4 \%$ for women, in which all obese men have a waist circumference more than $90 \mathrm{~cm}$, and 62 out of 63 obese women have a waist circumference of more than $80 \mathrm{~cm}$. Among abdominally obese men and women, majority are below 40 years old (men $=80 \%$, women=71.3\%), married (men=73.3\%, women= $52.4 \%)$, employed $(\operatorname{men}=73.3 \%$, women $=49.2 \%)$, degree holder $(m e n=30 \%$, women $=33.3 \%$ ) and obese class I (men=86.7\%, women=77.8\%). At one point, abdominally obese men and women shared different characteristic as the majority of abdominally obese men have a monthly income between RM1,501 to RM3,000 (36.7\%) while abdominally obese women have a monthly income of less than RM1,500 (61.6\%). In short, it can be concluded that there is a high prevalence of abdominal obesity among obese class I and II adults.
Moreover, Table IV shows the prevalence of elevated hs-CRP level among obese adults. Based on the table, the prevalence of elevated hs-CRP level was higher among obese women $(47.3 \%)$ as compared to obese men (12.9\%). Majority of obese adults that have elevated hs-CRP level were below 40 years old $(45.2 \%)$, married $(35.3 \%)$, employed (35.5), degree holder $(21.5 \%)$, with monthly income of less than RM1,500 (31.2\%) and BMI level between 27.5 to 34.9 $\mathrm{kg} / \mathrm{m}^{2}(45.2 \%)$. Another significant finding of this study is the distribution of risk estimate of future cardiovascular disease (CVD) events based on the hsCRP level (see Figure 1). The risk estimation was determined using the cut-off points of 0.1-0.7 (low), 0.7-1.1 (mild), 1.2-1.9 (moderate), 2.0-3.8 (high), 3.8-15.0 highest) to classify the participants based on their risk of future CVD events. ${ }^{22}$ Figure 1 shows that the distribution of risk borne by the obese men and women in this study peak at the highest risk of having future CVD event. A total of $58.7 \%$ of obese women and $33.3 \%$ of obese men have the highest risk of getting future CVD event.

Table III. Distribution of waist circumference and hs-CRP among obese men and women $(\mathrm{n}=93)$

\begin{tabular}{|c|c|c|c|c|c|c|c|c|}
\hline \multirow{2}{*}{ Gender } & \multicolumn{3}{|c|}{$\begin{array}{l}\text { Waist circumference measurement } \\
(\mathrm{cm})\end{array}$} & \multicolumn{3}{|c|}{$\begin{array}{l}\text { High sensitivity C-reactive protein } \\
\text { level } \\
(\mathrm{mg} / \mathrm{L})\end{array}$} & \multicolumn{2}{|c|}{$\begin{array}{l}\text { Kendall's Tau } \\
\text { correlation }\end{array}$} \\
\hline & Mean (SD) & $\begin{array}{l}\text { Median } \\
\text { (IQR) }\end{array}$ & p-valuea & Mean (SD) & $\begin{array}{l}\text { Median } \\
\text { (IQR) }\end{array}$ & p-valuea & $\mathrm{R}$ & $p$-value \\
\hline $\begin{array}{l}\text { Total } \\
(n=93)\end{array}$ & $\begin{array}{l}97.01 \\
(8.60)\end{array}$ & $\begin{array}{l}96.0 \\
(91.3 \\
101.3)\end{array}$ & & $6.47(6.34)$ & $\begin{array}{l}3.80 \\
(1.5 \\
10.1)\end{array}$ & & 0.075 & 0.291 \\
\hline $\begin{array}{l}\text { Men } \\
(n=30)\end{array}$ & $\begin{array}{l}102.98 \\
(8.65)\end{array}$ & $\begin{array}{l}100.75 \\
(95.0 \\
107.5)\end{array}$ & $0.001^{* *}$ & $3.83(4.01)$ & $\begin{array}{l}2.55 \\
(1.0,6 \\
1)\end{array}$ & $0.005^{*}$ & 0.355 & $0.006^{*}$ \\
\hline $\begin{array}{l}\text { Women } \\
(n=63)\end{array}$ & $\begin{array}{l}94.17 \\
(7.03)\end{array}$ & $\begin{array}{l}94.0 \\
(88.5 \\
98.5)\end{array}$ & & $7.72(6.87)$ & $\begin{array}{l}5.80 \\
(2.1,11 \\
.5)\end{array}$ & & 0.177 & $0.043^{*}$ \\
\hline
\end{tabular}

\section{DISCUSSION}

This study showed that there is a high prevalence of class I and II AO among Malay adults in Kuantan. Based on the National Health and Morbidity Survey 2015 (NHMS 2015), it was reported that on average, more than $48 \%$ of Malaysian adults are abdominally obese (AO). ${ }^{20}$ Also, the report showed that Pahang was listed among the top ten states that have the highest prevalence of $\mathrm{AO}(48.8 \%)$ with the highest rate in Putrajaya $(61.3 \%)$ and the least in Kelantan (39\%). In 2006, NHMS reported that the prevalence of overall $\mathrm{AO}$ was $17.4 \% .^{24}$ The prevalence rates indicate that there is an approximately $95 \%$ increase in the number of adults with $\mathrm{AO}$ in Malaysia since last decades. Therefore, this is a serious public health issue as the prevalence of $\mathrm{AO}$ in Malaysian adult seems to be increasing along with the mortality rate due to the endocrine, nutritional and metabolic diseases (2010: 1.72\%, 2012: 1.88\%, 2014: 2.05\%, and 2016: $2.08 \%$ ). According to the Health Indicator 2016 report, there are 351 cases of obesity discharge from Ministry of Health hospitals and three deaths due to obesity in $2015^{25}$, which shows that obesity itself is a fatal condition. Besides, it can be anticipated that the mortality rate due to obesity will continue to rise as the prevalence of $\mathrm{AO}$ increases by years. Thus, the alarming level of abdominal obesity among Malaysian adults needs to be reduced to tackle this issue.

In addition, this study found that obese men with higher income and obese women with lower income tend to have $\mathrm{AO}$. The findings support the theory that $A O$ may affect men and women with different socioeconomic position (higher education, standard 
employment status, and higher income quartile) in a different degree. ${ }^{26}$ This could be explained by the difference in eating pattern between men and women. Referring to the Malaysian Nutritional Adults Survey 2014 (MANS 2014), the report stated that more men than women tend to skip a meal and have an insufficient quantity and variety of food in the event of financial constraint. ${ }^{27}$ Besides, this study shows that on average, both obese men and women have elevated WC measurements.
Therefore, this study suggests that intervention should be planned to focus on these specific target population so that the obese adults are benefited and the incidence of obesity-induced CVD will be reduced.

On average, the hs-CRP level of obese men and women in this study is $2.55 \mathrm{mg} / \mathrm{L}$ and $5.80 \mathrm{mg} / \mathrm{L}$, respectively.

Table IV. Distribution of the study participants by the abdominal obesity and elevated hs-CRP status ( $\mathrm{n}=93$ )

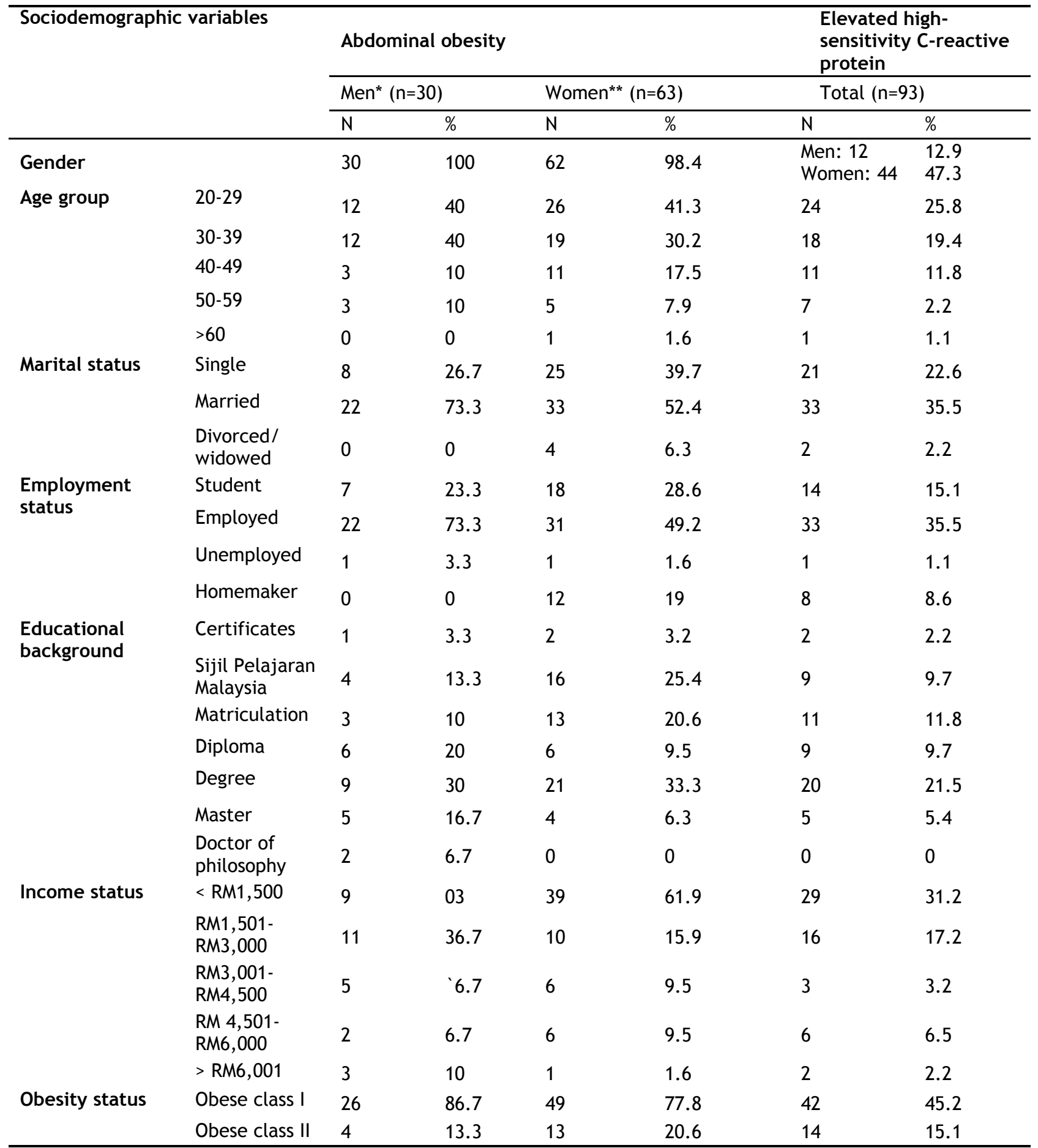

Note:

The Asian cut-off points for abdominal obesity are based on the Clinical Practice Guideline for the Management of Obesity, * Cut-off point of abdominal obesity in Asian men is waist circumference $>90 \mathrm{~cm}$,

** Cut-off point of abdominal obesity in Asian women is waist circumference $>80 \mathrm{~cm}^{3}$

Elevated hs-CRP cut-off point ( $>3 \mathrm{mg} / \mathrm{L})$ to indicate a low-grade inflammation in healthy adults ${ }^{21}$ 
Risk estimation based on hs-CRP level among obese men and women

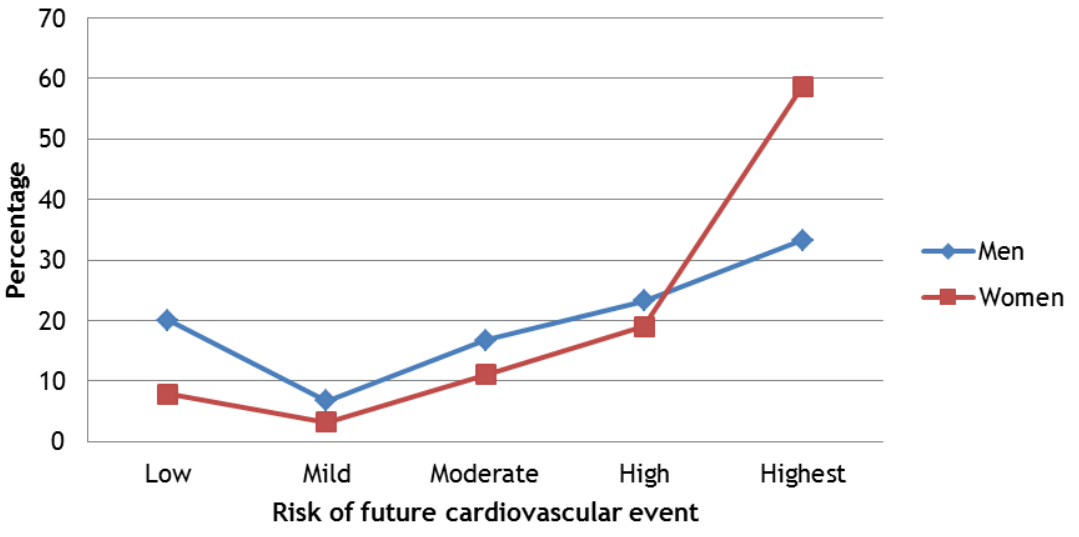

Figure 1. Classification of risk estimate based on the hs-CRP level among obese men and women ( $n=93)$

In comparison, the participants of this study have higher hs-CRP level, especially when compared to the median hs-CRP level among healthy South Asian men $(n=28)$ and women $(n=28)$, which are 1.07 (IQR: $0.76-1.50$ ) and 1.35 (IQR: 0.72 - 3.04), respectively ${ }^{28}$ and among Spanish Mediterranean men $(n=505)$ and women $(n=652)$, which are 1.38 $\mathrm{mg} / \mathrm{L}(0.65,3.16)$ and $1.64(0.75,3.45) .{ }^{29}$ On the contrary, the participants of this study have a lower hs-CRP level as compared to the median hs-CRP level of 390 healthy obese adults from University of Pennsylvania Health System that is $5.6 \mathrm{mg} / \mathrm{L}$ $(I Q R=3.1,10.2) .^{30}$ Thus, these findings suggest that the obesity status itself plays a major role as compared to races and age in order to determine the hs-CRP level in adults. In Malaysia, obtaining serum hs-CRP test was not done routinely to estimate the risk of future CVD in obese adults. Therefore, this study recommends the Malaysian healthcare system to take into account hs-CRP testing when providing health screening for obese adults.

Also, the current study found a statistically significant positive linear relationship between waist circumference measurement and hs-CRP level in both obese men and women. This finding is consistent with those of Sanip, Ariffin, Al-Tahami, Sulaiman, \& Rasool, who found hs-CRP level was positively correlated with waist circumference among ninety-one overweight to obese $(B M I>25$ $\mathrm{kg} / \mathrm{m}^{2}$ ) women from Kelantan, Malaysia $(\mathrm{r}(91)=$ $0.340, p=0.001) .{ }^{31}$ This finding also indicates that the relationship between waist circumference and the hs-CRP level is significant in obese men. Overall, this study suggests that higher waist circumference in obese men and women promote inflammation. Thus, measuring the hs-CRP level as an indicator of inflammation might be useful to predict the cardiovascular risk of the obese adult population. According to Taverne et al., having an hs-CRP level tested is beneficial to predict the future CVD events in the absence of serum lowdensity lipoprotein test result. ${ }^{5}$ Finally, interventions targeting abdominally Malay obese adults with the elevated hs-CRP level in Kuantan might be the key to a successful mission of reducing the prevalence of abdominal obesity and endocrine, nutritional and metabolic diseases as well as cardiovascular diseases in Pahang.

\section{Limitation of study}

The limited sample size should be considered in interpreting the results. The small sample size, especially in obese men, may underestimate the relationship between waist circumference and hsCRP level in obese adults. Hence, future studies with a larger sample size are highly recommended to confirm these findings.

\section{Conclusion and recommendation}

In conclusion, there is a significant increasing trend between abdominal adiposity and low-grade inflammation among Malay obese class I and II adults in Kuantan. The findings suggest that the accumulation of adipose tissue in the abdominal area may be contributed to low-grade chronic inflammation. Thus, intervention targeted at waist circumference reduction may lower the cardiovascular risk among Malay obese adults in Kuantan. Also, hs-CRP level testing should be a routine screening in obese adult, so that appropriate intervention is prompted based on the risk assessment. Future prospective study on the clinical application of hs-CRP level as a biomarker to the cardiovascular event among obese adults in Malaysia is recommended.

\section{ACKNOWLEDGEMENTS}

This work has been supported by IIUM under the Research Initiative Grant Scheme (RIGS) with project ID RIGS 16-283-0447.

\section{REFERENCES}

1. Planning Division Ministry of Health Malaysia. Health Facts 2016. Kuala Lumpur; 2016.

2. Cefalu WT. Classification and Evolution of Increased Cardiometabolic Risk States. In: Cefalu 
WT, Cannon CP, eds. Atlas of Cardiometabolic Risk. New York: Informa Healthcare; 2007:13-26.

3. Ministry of Health Malaysia. Clinical Practice Guidelines on Management of Obesity.; 2004.

4. Després JP. Abdominal obesity: The most prevalent cause of the metabolic syndrome and related cardiometabolic risk. Eur Hear Journal, Suppl. 2006;8:4-12. doi:10.1093/eurheartj/ sul002.

5. Taverne F, Richard C, Couture P, Lamarche B. Abdominal obesity, insulin resistance, metabolic syndrome and cholesterol homeostasis.

PharmaNutrition. 2013;1:130-136.

6. McArdle M a., Finucane OM, Connaughton RM, McMorrow AM, Roche HM. Mechanisms of obesity -induced inflammation and insulin resistance: Insights into the emerging role of nutritional strategies. Front Endocrinol (Lausanne). 2013;4:1-23.

7. Ray KK, Cannon CP. Non-Traditional Risk Factors of Cardiometabolic Risk. In: Cefalu WT, Cannon $\mathrm{CP}$, eds. Atlas of Cardiometabolic Risk. New York: Informa Healthcare; 2007:87-104.

8. Ellulu MS, Patimah I, Khaza H, Rahmat A, Abed Y, Sci AM. Obesity and inflammation : the linking mechanism and the complications. Arc Med Sci. 2016.

9. De Berardis D, Aiello G, Serroni N, et al. Creactive protein: A literature review of its implications in psychiatric disorders. In: Nagasawa S, ed. C-Reactive Protein: New Research. New York: Nova Science Publishers, Inc.; 2009.

10. Yousuf O, Mohanty BD, Martin SS, et al. Highsensitivity C-reactive protein and cardiovascular disease: A resolute belief or an elusive link? J Am Coll Cardiol. 2013;62(5):397408.

11. Helal I, Zerelli L, Krid M, et al. Comparison of C -Reactive Protein and High-Sensitivity CReactive Protein Levels in Patients on Hemodialysis Imed. Saudi J Kidney Dis Transplant. 2012;23(3):477-483.

12. Ridker PM. Clinical application of C-reactive protein for cardiovascular disease detection and prevention. Circulation. 2003;107:363-369.

13. Choi J, Joseph L, Pilote L. Obesity and Creactive protein in various populations: $A$ systematic review and meta-analysis. Obes Rev. 2013;14(3):232-244.

14. De Schutter A, Kachur S, Lavie CJ, Boddepalli RS, Patel DA, Milani R V. The impact of inflammation on the obesity paradox in coronary heart disease. Int J Obes. 2016;40 (11):1730-1735.

15. Ridker PM. C-reactive protein: a simple test to help predict risk of heart attack and stroke. Circulation. 2003;108:e81-e85.

16. Libby P. Inflammation and cardiovascular disease mechanisms. Am J Clin Nutr. 2006;83:456S-460S.

17. Ellulu MS, Khaza H, Rahmat A, Patimah I, Abed Y. Obesity can predict and promote systemic inflammation in healthy adults. Int $J$ Cardiol. 2016;215:318-324.

18. Rost NS, Wolf PA, Kase CS, et al. Plasma Concentration of $\mathrm{C}$-Reactive Protein and Risk of Ischemic Stroke and Transient Ischemic Attack: The Framingham Study. Stroke. 2001;32 (11):2575-2579.

19. Department of Statistics Malaysia. Population Quick Info: Population by ethnic group (Pahang). 2016. http://pqi.stats.gov.my/result. Accessed February 1, 2017.

20. Institute for Public Health (IPH). National Health and Morbidity Survey 2015 (NHMS 2015). Vol. II: Non-Communicable Diseases, Risk Factors \& Other Health Problems. (Aris T, Yusoff MFM, Ghani AAA, et al., eds.). Kuala Lumpur; 2015.

21. Nagasawa S. C-Reactive Protein: New Research. New York: Nova Science Publishers, Inc.; 2009.

22. Ridker PM. High-Sensitivity C-Reactive Protein: Potential Adjunct for Global Risk Assessment in the Primary Prevention of Cardiovascular Disease. Circulation. 2001;103:1813-1818.

23. WHO expert consultation. Public health Appropriate body-mass index for Asian populations and its implications for policy and intervention strategies. Lancet. 2004;363:157163.

24. Institute for Public Health (IPH). The Third National Health and Morbidity Survey 2006 (NHMS III): Executive Summary. Kuala Lumpur, Malaysia; 2008.

25. Ministry of Health $(\mathrm{MOH})$ Malaysia. Health Indicators 2016: Indicators for Monitoring and Evaluation of Strategy Health for All. 2016;16.

26. Yoo S, Cho HJ, Khang YH. General and abdominal obesity in South Korea, 1998-2007: Gender and socioeconomic differences. Prev Med (Baltim). 2010;51(6):460-465.

27. Institute for Public Health (IPH). National Health and Morbidity Survey 2014: Malaysian Adult Nutrition Survey (MANS). Vol. II: Survey Findings.; 2014.

28. Forouhi NG, Sattar N, McKeigue PM. Relation of $C$-reactive protein to body fat distribution and features of the metabolic syndrome in Europeans and South Asians. Int J Obes Relat Metab Disord. 2001;25(9):1327-1331.

29. García-Lorda P, Bulló M, Balanzà R, SalasSalvadó J. C-reactive protein, adiposity and cardiovascular risk factors in a Mediterranean population. Int J Obes. 2006;30(3):468-474.

30. Vetter M, Wadden T, Vinnard C, et al. Gender differences in the relationship between symptoms of depression and high-sensitivity CRP. Int J Obes. 2013;37:S38-S43.

31. Sanip Z, Ariffin FD, Al-Tahami BAM, Sulaiman WAW, Rasool AHG. Obesity indices and metabolic markers are related to hs-CRP and adiponectin levels in overweight and obese females. Obes Res Clin Pract. 2013;7(4):e315e320. 